\title{
Attenuation of Hippocampal Long-Term Potentiation by Ethanol: A Patch-Clamp Analysis of Glutamatergic and GABAergic Mechanisms
}

\author{
Richard A. Morrisett' and H. Scott Swartzwelder ${ }^{2,3}$ \\ 'Department of Pharmacology, University of Nebraska Medical Center, Omaha, Nebraska 68198-6260, ${ }^{2}$ Neurobiology \\ Research Laboratory, Veterans Administration Medical Center, Durham, North Carolina 27705, and ${ }^{3}$ Department of \\ Psychology, Duke University, Durham, North Carolina 27706
}

\begin{abstract}
Long-term potentiation of synaptic transmission (LTP) of the perforant path-dentate gyrus synapse is induced by $5 \mathrm{~Hz}$, theta-like stimulation patterns. Such stimuli induce plasticity that is most likely driven by a decrease in synaptic inhibition (disinhibition) mediated by $\mathrm{GABA}_{B}$ autoreceptors. In the present study, we demonstrate that LTP induced in this manner is completely antagonized by ethanol. In order to determine the site of ethanol inhibition of LTP induced by thetalike stimulation, we combined slice patch recordings with pharmacologic isolation of the individual glutamatergic and GABAergic synaptic currents. The present experiments revealed that ethanol inhibited NMDA receptor-mediated synaptic currents without potentiation of $\mathrm{GABA}_{A}$ currents or attenuation of $G_{A B A_{B}}$-mediated fading of $\mathrm{GABA}_{\mathrm{A}}$ synaptic currents. These observations with ethanol contrasted with the actions of the water-soluble benzodiazepine midazolam, which strongly potentiated $\mathrm{GABA}_{\mathrm{A}}$ synaptic currents, reversed the effect of $\mathrm{GABA}_{B}$-mediated fading of $\mathrm{GABA}_{A}$ synaptic currents, and therefore blocked the resulting NMDA synaptic currents. These data indicate that the effects of ethanol on long-term changes in synaptic strength in the rat hippocampal formation are due primarily to an action at the NMDA receptor-channel complex.
\end{abstract}

[Key words: ethanol, long-term potentiation, plasticity, glutamate, GABA, benzodiazepine, synaptic current, patch clampl

Memory impairment is one of the principle cognitive effects of ethanol abuse. The deleterious effects of ethanol on memory may be observed after acute (Mello, 1972), chronic (Walker and Hunter, 1978), or prenatal exposure (Streissguth et al., 1990). It is generally agreed that synaptic plasticity is one of the fundamental neural processes that are related to memory. However, until recently the neuronal effects of ethanol were thought to be quite nonspecific and few studies were made of ethanol effects on neuronal or network plasticity. It is now clear that several manifestations of neuronal plasticity including long-term po-

\footnotetext{
Received Aug. 27, 1992; revised Dec. 2, 1992; accepted Dec. 8, 1992.

This work was supported by a National Research Service Award (R.A.M.), the State of Nebraska (R.A.M.), the Alcohol Beverage Medical Research Foundation (R.A.M.), and the National Institute of Alcohol Abuse and Alcoholism (AA 07207 to H.H.S. and AA 09230 to R.A.M.). We thank Wilkie Wilson and David Mott for helpful review, discussion, and technical advice.

Correspondence should be addressed to Richard Morrisett, Ph.D., Department of Pharmacology, University of Nebraska Medical Center, 600 South 42nd Street, Omaha, NE 68198-6260.
}

Copyright $\odot 1993$ Society for Neuroscience $0270-6474 / 93 / 132264-09 \$ 05.00 / 0$ tentiation of synaptic transmission (LTP) (Durand and Carlen, 1984; Sinclair and Lo, 1986; Mulkeen et al., 1987; Swartzwelder et al., 1988; Blitzer et al., 1990), neuronal development (Streissguth et al., 1978; West et al., 1981), and the induction/expression of epileptiform responses (Grant et al., 1990; Morrisett et al., 1990; Cohen et al., 1991) are known to be altered by ethanol exposure.

Of these plasticity processes, LTP has been shown to correlate with acquisition of several learning tasks (Barnes et al., 1979; Berger, 1984; Morris et al., 1986) and has been proposed as a fundamental neural underpinning of memory formation (Teyler and DeScenna, 1984, 1985). In most neural circuits where it is manifested, the induction of LTP is dependent upon NMDA receptor-mediated activity (Collingridge et al., 1983), and the activation of NMDA receptors has been shown to be critical for certain types of memory (Morris et al., 1986). Recently, ethanol has been shown to antagonize NMDA-mediated neuronal activity selectively (Hoffman et al., 1989; Lima-Landman and Albuquerque, 1989; Lovinger et al., 1989, 1990; Woodward and Gonzales, 1990). It has been hypothesized that this antagonism may be responsible for ethanol attenuation of LTP (Lovinger et al., 1990). However, in addition to glutamatergic influences, GABAergic activity also plays a fundamental role in the induction of LTP (Wigstrom and Gustafsson, 1983), and ethanol is known to potentiate GABA-mediated processes (Allan and Harris, 1986; Suzdak, 1986; Ticku, 1987). Therefore, the relative contribution of glutamatergic and GABAergic mechanisms to the attenuation of LTP by ethanol remains unclear.

All of the previous reports regarding ethanol and LTP have utilized high-frequency stimulus trains to elicit LTP. Although such stimulus trains were the methodological standard in LTP studies for many years, recent reports have indicated that the use of high-frequency trains is not an optimal paradigm for studying the mechanisms underlying this phenomenon. Highfrequency stimulus trains produce an artificial induction of the NMDA component of synaptic transmission due to temporal summation of the non-NMDA synaptic potentials (Herron et al., 1986). This results in depolarization of the target neuron and release of the voltage-dependent $\mathrm{Mg}^{2+}$ block of the NMDA channel (Nowak et al., 1984). Therefore, the effects of agents that may modify LTP development, such as those targeting GABAergic inhibition, may not readily be apparent due to the direct defeat of synaptic inhibition by high-frequency trains.

Recent reports have suggested that the expression of NMDA responses under physiologic conditions requires theta-like $(5$ Hz) stimulation patterns (Larson and Lynch, 1986; Davies et 
al., 1991; Mott and Lewis, 1991). Such responses are enabled by the fading of synaptic inhibition (disinhibition), which is likely mediated by a reduction of GABA release due to the activation of $\mathrm{GABA}_{\mathrm{B}}$ autoreceptors on inhibitory basket cell terminals (Diesz and Prince, 1989; Davies et al., 1990; Nathan and Lambert, 1990; Nathan et al., 1991). Theta-like (5 Hz) firing patterns are known to occur in the hippocampal formation (Vanderwolf, 1969; Winson, 1974), and such firing patterns have been directly associated with synaptic plasticity in vitro and in vivo (Diamond et al., 1988; Pavlides et al., 1988; Pacelli et al., 1989). Therefore, it is likely that theta-stimulation promotes $\mathrm{GABA}_{\mathrm{B}}$-mediated disinhibition resulting in the physiologic expression of NMDA-mediated synaptic responses and synaptic plasticity (Davies et al., 1991; Mott and Lewis, 1991). Therefore, $\mathrm{GABA}_{\mathrm{A}}, \mathrm{GABA}_{\mathrm{B}}$, and NMDA synaptic conductances would appear to be potential sites through which ethanol inhibits LTP. We feel that to understand the mechanism whereby ethanol attenuates hippocampal LTP due to theta stimulation, the effects of ethanol on the pertinent synaptic responses must be studied under circumstances in which these responses are normally expressed.

In the present study, we analyzed the mechanism whereby ethanol inhibits LTP in the molecular layer-dentate granule cell synapse using $5 \mathrm{~Hz}$, patterned stimulus trains. NMDA and GABAergic synaptic currents were pharmacologically isolated, and tight-seal whole-cell voltage-clamp recordings were made in hippocampal slices. We assessed the effects of ethanol on the critical synaptic currents that regulate the induction of plasticity, in the same synapse and under the same conditions that I.TP was blocked by ethanol. We now report that at the perforant pathdentate gyrus synapse, the block of synaptic plasticity by pharmacologic concentrations of ethanol is due to a specific action at the NMDA receptor-channel complex, and that effects of ethanol on GABAergic transmission cannot account for its ability to block LTP. In addition, these experiments provide a direct demonstration of ethanol-induced inhibition of NMDA receptor-mediated synaptic currents in situ.

Some of these results have previously been reported in abstract form (Morrisett et al., 1991a).

\section{Materials and Methods}

Slice preparation, recording, and stimulation. Slice preparation was performed as previously described (Morrisett et al., 1991b). Male SpragueDawley rats (12-30 d old; Charles River, Raleigh, NC, or SASCO, Omaha, NE) were used for this study. All incubations and recordings were performed in artificial cerebrospinal fluid (ACSF; containing, in mM, NaCl, 120; KCl, 3.3; $\mathrm{NaH}_{2} \mathrm{PO}_{4}, 1.23 ; \mathrm{NaHCO}_{3}, 25 ;$ dextrose, 10; continually gassed with $95 \% \mathrm{O}_{2}, 5 \% \mathrm{CO}_{2} ; \mathrm{pH} 7.4,32^{\circ} \mathrm{C}, 280-290 \mathrm{mOsm}$. Slices were prepared and incubated in ACSF containing $1.2 \mathrm{mM} \mathrm{Mg} \mathrm{Mg}^{2+}$ and $1.8 \mathrm{mM} \mathrm{Ca}^{2+}$. All recordings were made in $0.9 \mathrm{mM} \mathrm{Mg}^{2+}$ and 2.0 $\mathrm{mm} \mathrm{Ca}{ }^{2+}$ and were performed in superfusion chambers manufactured by either the Duke University Physiology Instrument Shop (Durham, NC; tubing and chamber volume, 7 and $4 \mathrm{ml}$, respectively) or from AM systems (Greenvale, NY; tubing and chamber volume, 5 and $2 \mathrm{ml}$, respectively). Flow rate for all recordings was $2.0-2.5 \mathrm{ml} / \mathrm{min}$ and was either gravity fed or pumped (Rainin Kabbit, Boston, MA). Both chambers were temperature regulated by a feedback circuit and was maintained at $32^{\circ} \mathrm{C}$ for all recordings. Monophasic, constant-current stimulus pulses were delivered through a tungsten stimulating electrode $(100 \mu \mathrm{sec}$, $100-1000 \mu \mathrm{A})$ and were generated with Grass S-88 or Dagan S-900 stimulators. Stimuli were delivered to the inner layer of stratum moleculare of dentate gyrus at $0.01 \mathrm{~Hz}$ as singles, pairs of varying interstimulus intervals $(20-2000 \mathrm{msec})$, or $5 \mathrm{~Hz}, 2 \mathrm{sec}$ trains. All drugs were from Tocris except ethanol (95\%), which was from either Duke University Medical Center Biochemical Supply or University of Nebraska
Medical Center Hospital Supply, and midazolam, which was the gencrous gift of Hoffmann-LaRoche Pharmaceuticals (Nulley, NJ).

Extracellular recording. Population field potentials were recorded from the strata moleculare and granulosum of the outer blade of the dentate gyrus using glass microelectrodes filled with $150 \mathrm{mM} \mathrm{NaCl}$ (1-3 MR). These recordings were made to (1) measure ethanol effects on synaptic plasticity elicited by paired-pulse stimulation, (2) pharmacologically characterize NMDA synaptic responses elicited by paired-pulse stimulation, and (3) measure ethanol effects on NMDA responses elicited by paired-pulse stimulation. Slices were discarded if either the maximal population field potential or the population spike amplitude was less than $3 \mathrm{mV}$. Responses were recorded on a Nicolet 310 digital oscilloscope and stored on floppy disk for subsequent analysis using WAVEFORM BASIC software on a PC-compatible computer. Hyperexcitability of dentate granule population responses was determined primarily by measuring the duration of the dendritic population EPSP (pEPSP). This duration was measured at $20 \%$ of the peak negativity of the pEPSP. Population spikes were measured by taking the average of both sides of the peak negativity between the two peak positivities that formed the somatic pEPSP. The pEPSP slope was measured over the initial 400-500 msec of the pEPSP downstroke.

LTP experiments were performed first by monitoring the field potentials (population spike and/or pEPSP amplitude and pEPSP slope) for at least $20 \mathrm{~min}$ after determining the input-output curve for each slice. Field responses were monitored at stimulus intensities that elicited a response $25 \%$ of the maximum amplitude. Upon demonstration of stability ( $25 \%$ response; variability $< \pm 10 \%)$, ethanol $(75 \mathrm{~mm})$ was bath applied and the response to the previous $25 \%$ test stimulus was determined for at least $20 \mathrm{~min}$ following wash-on of the ethanol. Then, one $5 \mathrm{IIz}, 2 \mathrm{sec}$ train at $100 \%$ maximum stimulus intensity (relative to preethanol stimulus input-output curve) was delivered. The ethanol was then immediately washed off, and the response to the preethanol exposure test stimulus was again measured for at least 20 min following washout of the ethanol. If the response returned to control levels, then another identical $(5 \mathrm{~Hz}, 2 \mathrm{sec}, 100 \%$ maximum) stimulus train was delivered and the responses measured for at least $20 \mathrm{~min}$. LTP was defined as nondecremental synaptic potentiation lasting at least 45 min with at least a $25 \%$ increase in the population spike amplitude and pEPSP slope.

Patch-clamp recording. Tight-seal recordings in the whole-cell mode were utilized to determine which synaptic currents were modificd by ethanol exposure, as described by Hamill et al. (1981) and Blanton et al. (1989). These recordings were made in transverse slices prepared in exactly the same manner as for extracellular recordings. Slices were perfused with normal ACSF (280-290 mOsm). Glass thin-wall microelectrodes (World Precision Instruments, TW1 50F-4) were pulled on a Brown-Flaming model P-88 electrode puller (Sutter Instrument Co., San Rafael, CA) using a $3 \mathrm{~mm}$ box filament and a five-step program giving an electrode resistance of 1-2 M . Electrodes were filled with (in mм) $\mathrm{KMeSO}_{4}$, 140; $\mathrm{KCl}, 10$; EGTA, 11; HEPES, $10 ; \mathrm{MgCl}_{2}, 2 ; \mathrm{CaCl}_{2}$, 1; Tris-ATP, 4; Tris-GTP, 2; 260-270 mOsm. All intracellular solutions were filtered and buffered to 7.2 with $\mathrm{KOH}(1 N)$. Electrodes were not fire polished or Sylgarded. Synaptic currents were amplified using a Dagan 3900A patch-clamp amplifier (Dagan Corp., Minneapolis, MN) in mixed (RC) mode and recorded on digital audiotapc (Sony DAT, Dagan Corp.) for off-line analysis. Cells had 1.3-5.4 G $\Omega$ sealing resistance, and upon rupture the input resistance was $235 \pm 5 \mathrm{M} \Omega ; n=32$. Input resistance was continuously monitored throughout the experiment and the recording terminated if $R_{\text {in }}$ varied by more than $20 \%$. Series resistance ranged from 7 to $16 \mathrm{~m} \Omega$ and compensation was $>70 \%$. Synaptic currents were filtered at $1-5 \mathrm{kHz}$ using a four-pole Bessel filter, digitized at $22 \mathrm{kHz}$ (Sony DAT, low-speed recording), and measured at peak amplitude relative to the baseline current preceding the stimulus, and were normally evoked at low stimulus intensity $(50-200 \mu \mathrm{A})$.

\section{Results}

As described above, several studies have shown that "conditioning" paradigms utilizing patterned, $5 \mathrm{~Hz}$ stimulus trains can induce LTP by virtue of $\mathrm{GABA}_{\mathrm{B}}$-mediated disinhibition and the resultant incrcasc in NMDA synaptic responses. We hypothesized that ethanol would inhibit LTP induced by $5 \mathrm{~Hz}$ trains delivered to the perforant path-dentate gyrus synapse. The results of this experiment are shown in Figure 1. Test stimuli 
A

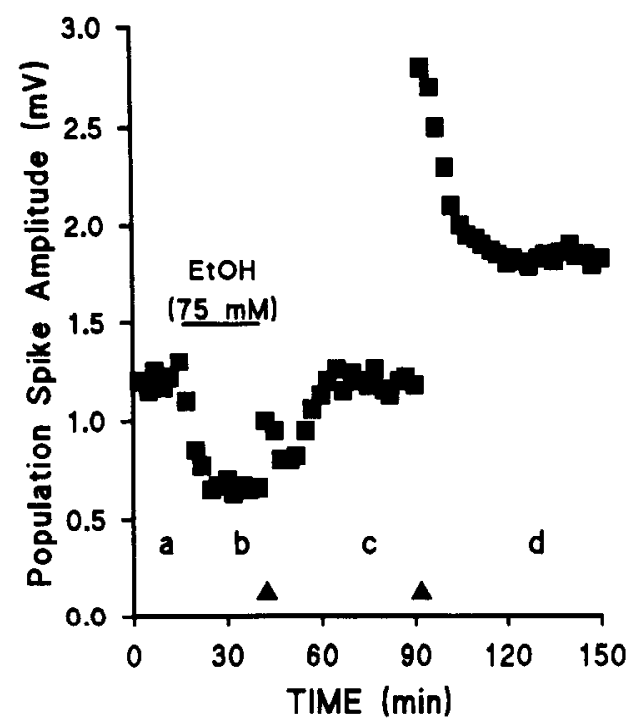

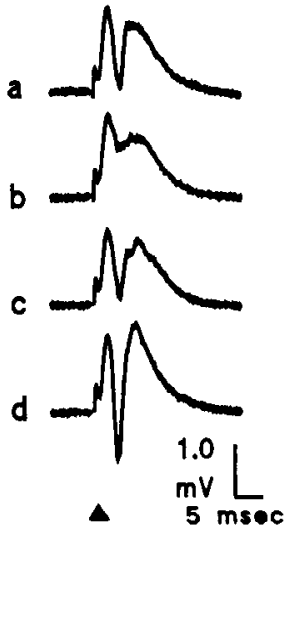

B

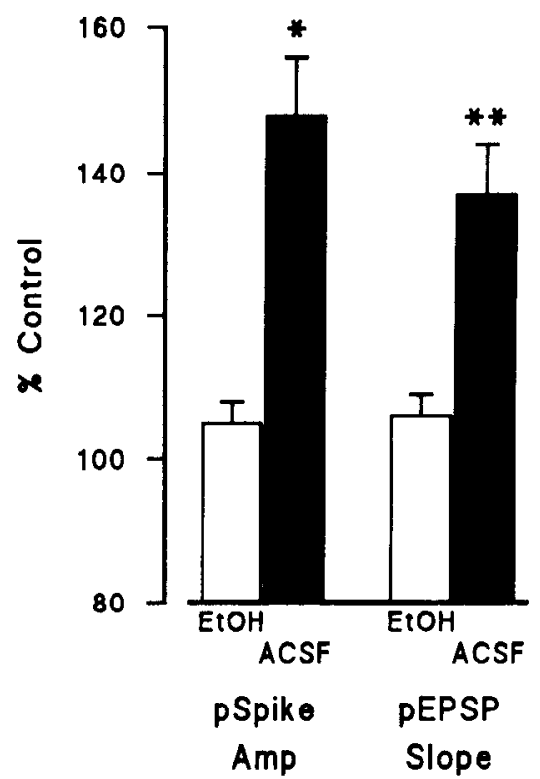

Figure 1. Plasticity of molecular layer-granule cell synapse induced by $5 \mathrm{~Hz}$ trains is blocked by ethanol. $A$, Plot of population spike amplitude evoked by $225 \mu \mathrm{A}$ delivered to the molecular layer at $0.01 \mathrm{~Hz}$. Letters $(a-d)$ correspond to individual field recordings at right. Responses initially (0-15 min) were recorded in normal ACSF. $a$, Control response in top tracing is a stable $25 \%$ maximal response elicited in ACSF. Then, ethanol ( $75 \mathrm{~mm}$ ) was applied, resulting in this case in a $50 \%$ decrease in population spike amplitude (b). Application of $5 \mathrm{~Hz}$ trains for 2 sec (10 pulses at $800 \mu \mathrm{A})$ in ethanol had little effect on the evoked response. The responses returned to control levels after wash of ethanol $(c)$. A second application of the identical $5 \mathrm{~Hz}$ train in ACSF first resulted in a decremental form of synaptic plasticity that later stabilized at an enhanced efficacy (d). $B$, Nondecremental LTP induced by $5 \mathrm{~Hz}$ trains is blocked by ethanol: bar graphs of enhancement of population spike amplitude and pEPSP slope after $5 \mathrm{~Hz}$ trains in ethanol and normal ACSF in all slices tested. All slices were treated with ethanol ( $75 \mathrm{~mm}$ ) and delivered 2 sec, $5 \mathrm{~Hz}$ trains, and then washed and administered the identical train again $\left({ }^{*}, p<0.005, n=7\right.$ slices; ${ }^{* *}, p<0.01, n=6$ slices, Kruskal-Wallis).

were administered to naive slices, then ethanol $(75 \mathrm{~mm})$ was bath applied. Ethanol had inhibitory effects on synaptic responses dependent upon the stimulus intensity. For example, in the 14 slices studied for the LTP experiments in Figure 1 and the ethanol dose-response experiments shown in Figure 3, ethanol ( $75 \mathrm{~mm}$ ) decreased the amplitude of the population spike evoked by low-level stimuli ( $25 \%$ maximal response) by $37 \pm$ $2 \%$ (mean \pm SEM). However, the amplitude of the maximal population spike response was inhibited by only $12 \pm 1 \%$.

In the presence of ethanol $(75 \mathrm{~mm})$, a $5 \mathrm{~Hz}, 2 \mathrm{sec}$ train was delivered at the stimulus intensity (normally $800-1000 \mu \mathrm{A}$ ) that produced the maximal population spike. Ethanol was washed out of the bath immediately after the stimulus train was applied. After a stable baseline was reestablished, an identical $5 \mathrm{~Hz}, 2$ sec train was applied to the slice. Figure $1 A$ shows the results of a typical LTP experiment. Ethanol inhibited the test population spike amplitude by approximately $50 \%$ (compare traces at points $\mathbf{a}$ and $\mathbf{b}$ ), but after washout of ethanol following the stimulus train, the test stimulus evoked a response equivalent to baseline levels (trace $c$ ). The stimulus train initially induced a period of short-term potentiation that rapidly decremented during the ethanol washout. Subsequent administration of an identical train in control medium resulted in long-term, nondecremental potentiation of the synaptic response. Figure $1 B$ summarizes the results of the LTP experiments in all slices tested. The responses were simultaneously recorded from the molecular layer to monitor the pEPSP slope and from the granule cell layer to monitor the population spike amplitude. Neither of these measures were altered after stimulus trains were delivered in $75 \mathrm{~mm}$ ethanol. However, both the somatic and dendritic responses manifested significant synaptic potentiation under control conditions. In these experiments population spike amplitude was increased to an average of $148 \pm 8 \%(n=7)$ of baseline, while the pEPSP slope was increased to an average of $137 \pm 7 \%(n=6)$ of baseline.

In order to understand the mechanism of ethanol inhibition of LTP as shown in Figure 1, we first utilized extracellular recording techniques to measure ethanol effects on excitatory responses due to stimulation delivered at $5 \mathrm{~Hz}$ to the inner molecular layer of the dentate gyrus. Hyperexcitability of the synaptic responses could be demonstrated using extracellular recording at either somatic or dendritic sites. Figure $2 A$ depicts somatic responses elicited by pairs of stimuli, separated by an interval of $200 \mathrm{msec}$, in a control hippocampal slice. At this recording site, hyperexcitability is expressed primarily by repetitive population spikcs. Prolongation of the somatic synaptic field potential is also apparent. The repetitive cell firing was blocked by the $\mathrm{GABA}_{\mathrm{B}}$ receptor antagonist 2-hydroxy-saclofen $(200 \mu \mathrm{M})$. Note the minimal effect of the $\mathrm{GABA}_{\mathrm{B}}$ receptor antagonist on the first response of the pair. The NMDA receptor antagonist D-aminophosphonovalerate (D-APV) $(25 \mu \mathrm{M})$ also blocked the hyperexcitability of the paired response, leaving the initial response largely unaffected. The effects of both D-APV and 2-hydroxy-saclofen were completely reversible upon wash.

In Figure $2 B$, the effect of the $\mathrm{GABA}_{\mathrm{B}}$ receptor antagonist 2 -hydroxy-saclofen on responses elicited at various interstim- 

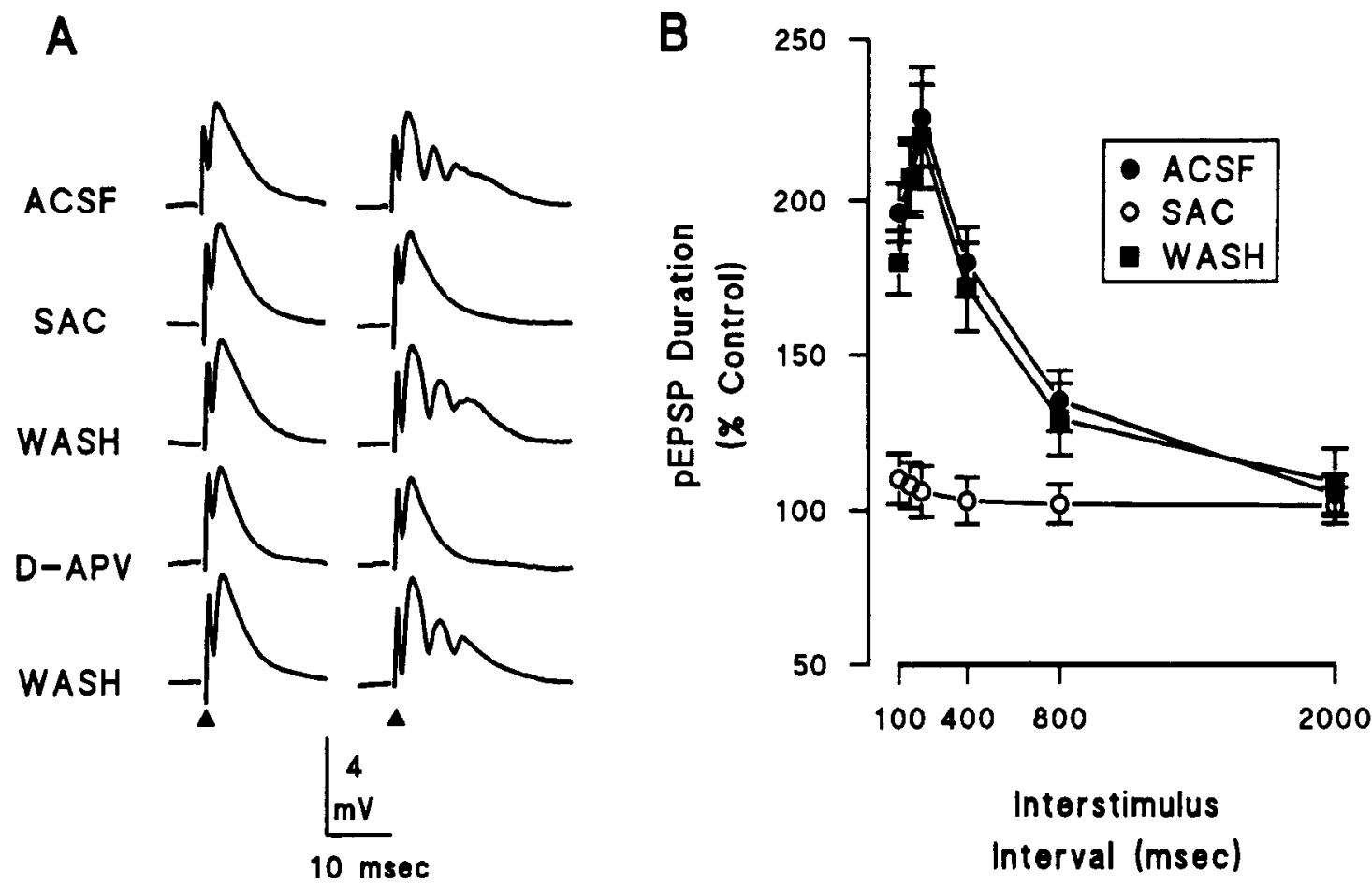

Figure 2. Hyperexcitability induced by a paired stimulation paradigm is due to activation of NMDA and GABA B $_{\mathrm{B}}$ receptors. $A$, Population spike recordings from dentate granule cell layer showing multiple population spikes when test stimulus was delivered 200 msec following the conditioning stimulus (triangles, i.e., $200 \mathrm{msec}$ interstimulus interval). All traces were elicited by delivering $800 \mu \mathrm{A}$ to the inner molecular layer of the dentate gyrus. $S A C$ represents responses evoked in the presence of 2 -hydroxy-saclofen $(200 \mu \mathrm{M})$. APV represents responses evoked in the presence of 2 -amino-5-phosphonovaleric acid $(25 \mu \mathrm{M})$. WASH represents responses evoked in normal ACSF following washout of test compounds from the bath normally requiring 5-10 min. $B$, Interstimulus interval plot demonstrating the dependence of hyperexcitability on the activation of GABA receptors. Hyperexcitability was quantified by determining the duration of the dendritic pEPSP at $20 \%$ of the maximum amplitude (see Fig. 2 ). $\%$ Control refers to the duration of the test response relative to the control (conditioning) response. Each data point reflects the mean of at least three determinations in each slice in each condition in six to eight slices. Paired stimulation at intervals from 100 to $400 \mathrm{msec}$ in $A C S F$ and $W A S H$ were not significantly different from each other, but were different from $S A C$ ( $p<0.001, n=6$, Kruskal-Wallis test) and from their respective conditioning responses ( $p<0.005, n=6$, Kruskal-Wallis test).

ulus intervals is shown diagramatically. In this case, stimulation at $5 \mathrm{~Hz}$ resulting in $\mathrm{GABA}_{\mathrm{B}}$-mediated disinhibition is demonstrated by measuring the prolongation of the dendritic field potential (pEPSP; see Fig. $3 A$ ). There was a strict time dependence of the prolongation of the pEPSP that peaked at intervals between 100 and $400 \mathrm{msec}$. The effects of pairing over this range of intervals were reversibly blocked by the $\mathrm{GABA}_{\mathrm{B}}$ receptor antagonist 2-hydroxy-saclofen. There was no apparent effect on pEPSP duration of varying the interstimulus interval in the presence of the $\mathrm{GABA}_{\mathrm{B}}$ receptor antagonist.

Figure $3 A$ illustrates the effects of ethanol (75 mM) upon GA$B A_{B}$-mediated hyperexcitability of responses from dendritic recording sites. In this particular slice, $5 \mathrm{~Hz}$ stimulation resulted in a threefold prolongation of the pEPSP that was substantially blocked by ethanol $(75 \mathrm{~mm})$ in a reversible manner. This effect of ethanol was typical with little effect on the peak pEPSP amplitude (which itself is insensitive to NMDA receptor antagonists; data not shown). In the lower traces of Figure 3A, the pEPSPs in ACSF and ethanol are superimposed, demonstrating more clearly the inhibitory effect of ethanol on the pEPSP duration. Figure $3 B$ shows the dose-response relationship for ethanol-induced attenuation of the paired-pulse disinhibition of the pEPSP. Ethanol inhibited the effect of $5 \mathrm{~Hz}$ stimulation in a dose-dependent manner over the range of concentrations tested (25-100 mM). The apparent $\mathrm{IC}_{50}$ of ethanol was approxi- mately $58 \mathrm{~mm}$ and the effect of ethanol reversed upon washout by more than $70 \%$ in every slice tested.

There are several mechanisms whereby ethanol could block the excitability induced by $5 \mathrm{~Hz}$ stimulation, and therefore the induction of LTP in these experiments. Ethanol could (1) potentiate $\mathrm{GABA}_{\mathrm{A}}$ conductances, (2) inhibit $\mathrm{GABA}_{\mathrm{B}}$-mediated fading of $\mathrm{GABA}_{\mathrm{A}}$ conductances, (3) inhibit NMDA conductances, or (4) have some combination of the above actions. In order to address these possibilities, we utilized tight-seal wholecell voltage-clamp recording in the same preparation used for the previous experiments. We combined this technology with pharmacologic isolation of the individual synaptic currents of interest to determine the site of action of ethanol at the perforant path-dentate gyrus synapse.

$\mathrm{GABA}_{\mathrm{A}}$ currents were isolated as described by Davies et al. (1990) using the excitatory amino acid receptor antagonists 6,7dinitroquinoxaline-2,3-dione (DNQX) and D-APV to block nonNMDA and NMDA receptors, respectively. Stimulation under these conditions results in the recording of a "monosynaptic" IPSC (mIPSC). This current is biphasic, with a rapid component that is blocked by picrotoxin (PTX) and a slow component that is blocked by 2 -hydroxy-saclofen (data not shown). Figure $4 A$ shows recordings collected at $-60 \mathrm{mV}$, a membrane potential that promotes recording of the fast $\mathrm{GABA}_{\mathrm{A}}$ component. When stimuli were delivered at $5 \mathrm{~Hz}$, a profound decrease in the am- 


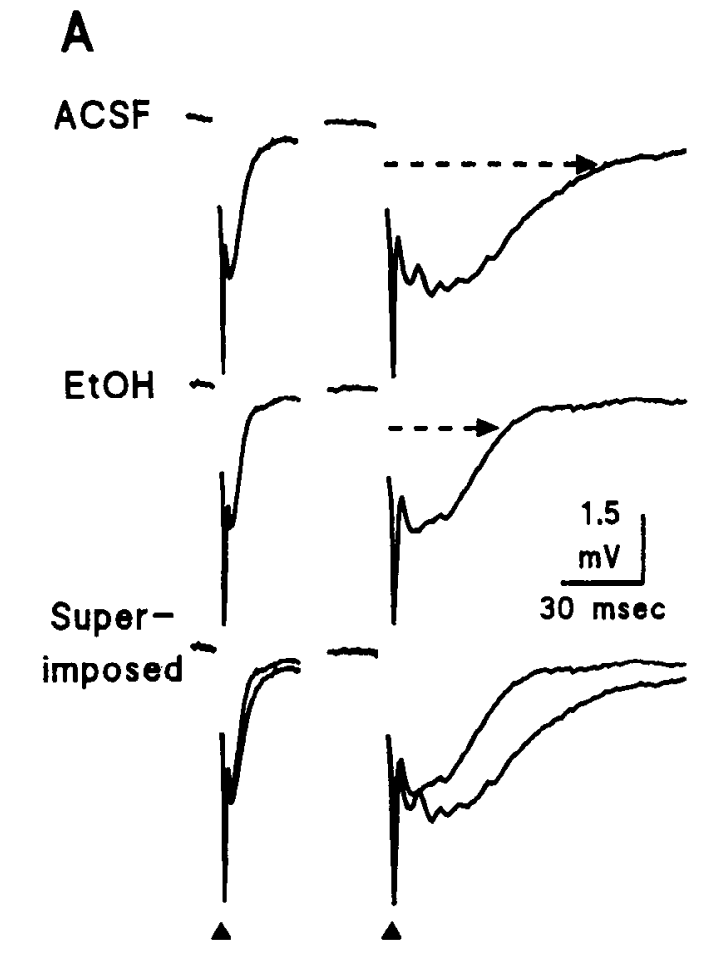

B

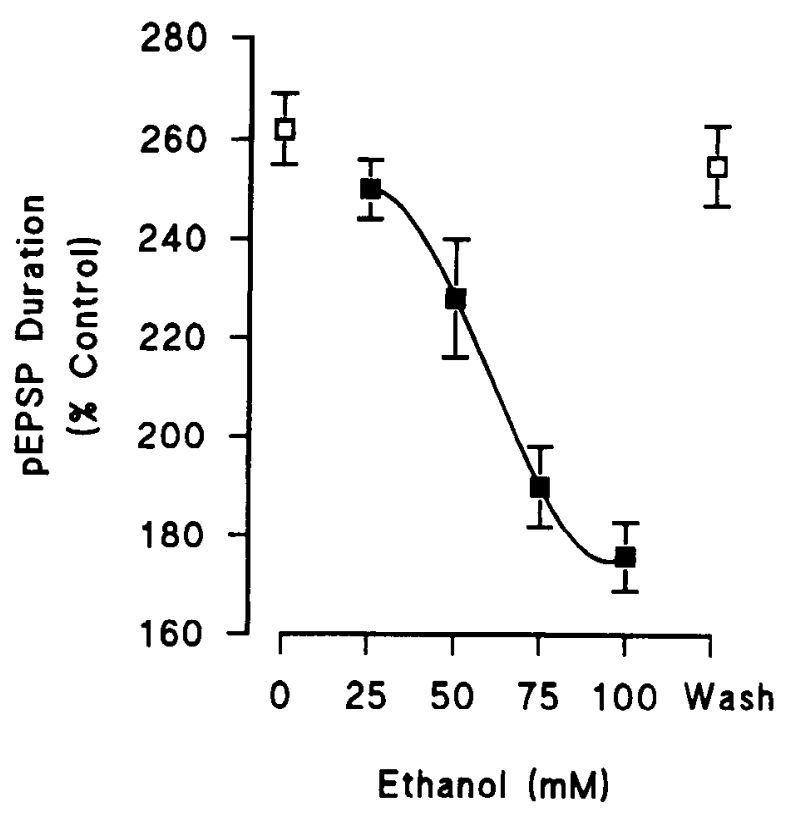

Figure 3. Ethanol blocks hyperexcitability due to paired stimulation of dentate molecular layer. $A$, Paired stimulation prolongs pEPSP duration (horizontal dashed line) measured at $20 \%$ of the maximum pEPSP amplitude. Ethanol $(75 \mathrm{~mm})$ antagonizcd pEPSP prolongation and repetitive firing with little effect on control response. $B$, Dose-response relationship of ethanol inhibition of NMDA-mediated hyperexcitability due to paired stimulation protocol at $5 \mathrm{~Hz}$. \% Control refers to the duration of the test response relative to the conditioning response. All slices were treated with ethanol in increasing concentrations (25-100 mM). WASH represents response to paired stimulation at $200 \mathrm{msec}$ following return to $A C S F$ perfusion. Responses recorded in 25-100 mM ethanol were significantly different from $A C S F$ and $W A S H(p<0.05$ for $25 \mathrm{~mm}, p<0.01$ for $50-100 \mathrm{~mm}, n$ = 5-7 slices, Kruskal-Wallis test).

plitude of the mIPSCs was apparent. This decrease in the IPSCs forms the basis for disinhibition and induction of NMDA synaptic currents. The strong fading of the mIPSCs was completely blocked by 2 -hydroxy-saclofen (SAC, bottom trace). In the presence of ethanol ( $75 \mathrm{~mm}$ ), there was no apparent change in either the mIPSC amplitude or time course evoked by a single stimulation. Neither did ethanol $(75 \mathrm{~mm})$ have any effect on the fading of the mIPSC due to $5 \mathrm{~Hz}$ stimulation. Figure $4 B$ shows the cumulative data obtained in the presence of DNQX/D-APV, ethanol, and 2-hydroxy-saclofen. The left panel demonstrates that the mIPSC evoked by a single stimulation was not significantly affected by the presence of ethanol (75 mM; $p>0.5, n$ $=8$ ). The right panel shows cumulatively the effect of ethanol and 2-hydroxy-saclofen on the fading of the mIPSC due to 5 $\mathrm{Hz}$ stimulation. Ethanol had no significant effect on mIPSC fading ( $n=8$ cells), whereas saclofen almost completely blocked the fading of the mIPSC. The effect of saclofen reversed upon washout in every case ( $n=5$ cells from different slices).

The mIPSC experiments strongly suggested that potentiation of GABAergic synaptic currents by ethanol was not responsible for the block of the hyperexcitability or LTP induced by $5 \mathrm{~Hz}$ stimulation. We therefore hypothesized that ethanol antagonism of NMDA currents at this synapse was a likely site of ethanol action. To investigate this possibility, we isolated NMDA synaptic currents under two different conditions. First, we used DNQX to block non-NMDA currents and stimulated at $5 \mathrm{~Hz}$ to allow the simultaneous fading of the IPSCs to promote the NMDA currents. Figure $5 A$ depicts NMDA currents evoked in this manner. In the presence of DNQX, small inward currents
(10-30 pA) were recorded after single stimuli when cells were held -70 to $-80 \mathrm{mV}$. Paired stimulation at $5 \mathrm{~Hz}$, however, rcsultcd in much larger inward currents $(60-120 \mathrm{pA})$. D-APV inhibited the response to the initial stimulation by $60-80 \%$, and reduced the response to the paired stimulation to the amplitude of that induced by the first stimulus of the pair (data not shown). This indicates that the increase in synaptic current evoked at 5 $\mathrm{Hz}$ was almost completely mediated by NMDA receptors. Ethanol $(75 \mathrm{mM})$ strongly inhibited the response recorded in DNQX to both single and $5 \mathrm{~Hz}$ stimulation in all cells tested $(n=9)$ and across the range of membrane potentials tested ( -40 to $-100 \mathrm{mV}$ ). The effect of ethanol always reversed upon wash to more than $70 \%$ of the control response.

In order to ensure that we had the capability to resolve the actions of positive allosteric modulators of the $\mathrm{GABA}_{\mathrm{A}}$ channel complex on the expression of NMDA synaptic currents, we studied the action of the water-soluble benzodiazepine midazolam. Figure $5 B$ is a recording from another cell in DNQX showing a typical effect of midazolam. The cell presented in this figure was held at $-60 \mathrm{mV}$ in order to better resolve the outward $\mathrm{GABA}_{\mathrm{A}}$ current evoked by the initial stimulus, while still observing the inward NMDA current induced by the stimulation at $200 \mathrm{msec}$. Under these conditions midazolam $(30 \mu \mathrm{M})$ strongly potentiated the outward synaptic current (presumably due to the enhancement of $\mathrm{GABA}_{\mathrm{A}}$ currents). Note that midazolam increased the peak synaptic current amplitude and prolonged the decay of the current evoked by the initial stimulus. Interestingly, the potentiation by midazolam of the outward synaptic current was so complete that fading of the IPSC due to $5 \mathrm{~Hz}$ 

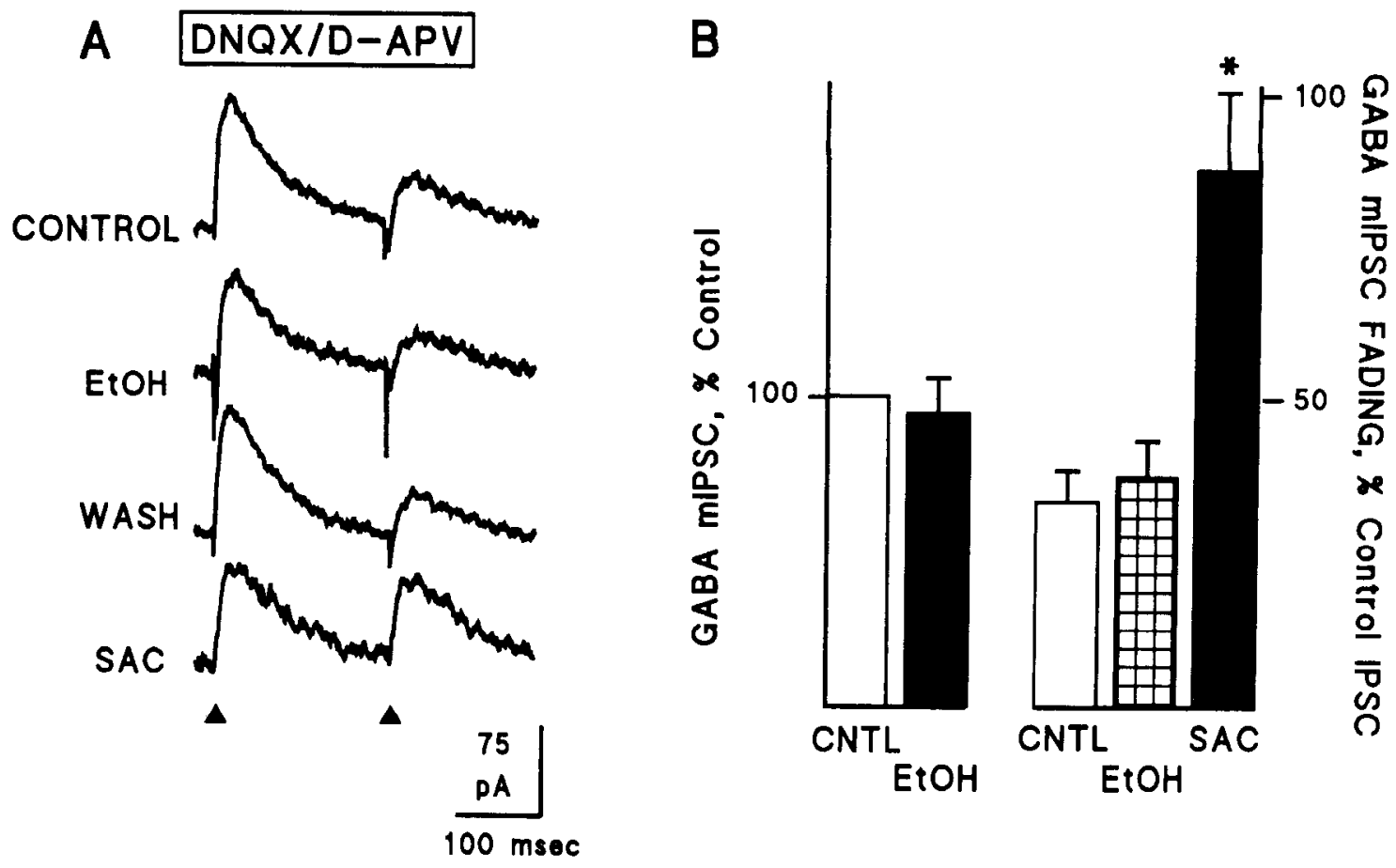

Figure 4. Lack of an effect of ethanol on mIPSCs at molecular layer-dentate gyrus synapse. $A$, Whole-cell recording of mIPSCs pharmacologically isolated using the glutamate receptor antagonists DNQX $(10 \mu \mathrm{M})$ and D-APV $(10 \mu \mathrm{M})$. Recordings were made at $-60 \mathrm{mV}$. Note the fading of the second mIPSC due to paired stimulation at $5 \mathrm{~Hz}$. Ethanol $(75 \mathrm{~mm})$ had no effect on the control mIPSC or the effect of pairing stimuli at $5 \mathrm{~Hz}$. However, 2-hydroxy-saclofen $(S A C, 200 \mu \mathrm{M})$ completely reversed the fading that returned upon 2-hydroxy-saclofen wash (data not shown). $B$, Bar graphs of the effect of ethanol on mIPSCs and comparing the effect of ethanol and 2-hydroxy-saclofen on mIPSCs. On left panel of $B$, the effect of ethanol (75 mM) on the peak mIPSC amplitude is shown relative to the control (preethanol exposure). There was no difference between the control and ethanol groups ( $p>0.5, n=8$ cells from different slices). On the right panel of $B$, the effect of ethanol and 2-hydroxy-saclofen on fading of the mIPSCs due to $5 \mathrm{~Hz}$ stimulation is presented, calculated as peak amplitude of $\mathrm{mIPSC}_{2} / \mathrm{mIPSC}_{1}$. Ethanol had no effect on fading of mIPSCs $(p$ $>0.5, n=8$ ), while 2 -hydroxy-sacloten reversed fading of mIPSCs to a significant degrce ( ${ }^{*}, p<0.01, n=5$, Kruskal-Wallis).

stimulation was not apparent. To assess the effect of midazolam on the predominant $\mathrm{GABA}_{\mathrm{A}}$ currents, cells were held at -60 $\mathrm{mV}$; in this case midazolam potentiated the pcak outward IPSC due to single stimulation by $39 \pm 6 \%$ ( $p<0.01$, Kruskal-Wallis; $n=5$ ). When stimuli were paired at $5 \mathrm{~Hz}$, the induction of the inward synaptic current (presumably due to the predominant action of NMDA-coupled channels) was completely blocked by midazolam, resulting in a reversal of the current direction. In order to measure the effect of midazolam $(30 \mu \mathrm{M})$ on the inward currents, cells were held at $-90 \mathrm{mV}$ to $-100 \mathrm{mV}$; under such conditions, midazolam almost completely inhibited the peak NMDA EPSC amplitude due to $5 \mathrm{~Hz}$ stimulation $(83 \pm 9 \%$ inhibition; $p<0.01$, Kruskal-Wallis; $n=5$ ).

The data presented in Figure 4 indicate that ethanol did not

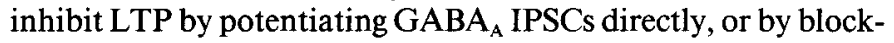
ing the fading of $\mathrm{GABA}_{\mathrm{A}}$ IPSCs. The results from Figure $5 \mathrm{~A}$ suggested that the primary action of ethanol was at the NMDA receptor-channel complex. In order to demonstrate this further, we pharmacologically isolated NMDA EPSCs under conditions

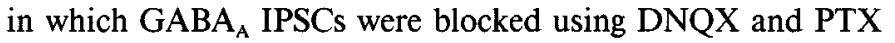
(Morrisett et al., 1991b). Under these conditions inward currents were evoked in several cells by single stimuli (Fig. $5 C$ ). Ethanol (75 mM) strongly inhibited the NMDA EPSC recorded in DNQX/ PTX $(n=6)$. The effect of ethanol was reversible in every case and the NMDA EPSC was also completely blocked by D-APV $(25 \mu \mathrm{M})$. The cumulative results of the DNQX and DNQX/PTX synaptic current experiments are presented in Figure $5 D$. In the left panel of the graph, the DNQX synaptic currents were evoked at $5 \mathrm{~Hz}$. The right panel of Figure $5 \mathrm{D}$ shows the effect of ethanol
(75 mM) on NMDA currents evoked by single stimuli recorded in DNQX/PTX.

Some preparations were stably maintained for a sufficicnt time to analyze the effect of ethanol on both the NMDA and mIPSCs in the same cell $(n=4)$. In these cases, cells were first treated with DNQX and $5 \mathrm{~Hz}$ stimulation was given in the absence and presence of ethanol. Ethanol (75 mM) significantly inhibited NMDA EPSCs recorded in these cells under these conditions. Then, the cells were treated with DNQX/D-APV to isolate the mIPSCs and study the effects of ethanol. As presented in Figure 4, neither mIPSCs nor fading of mIPSCs due to $5 \mathrm{~Hz}$ stimulation appeared sensitive to ethanol $(75 \mathrm{mM})$. Therefore, ethanol had no consistent or significant effect on the $\mathrm{GABA}_{\mathrm{A}}$ mIPSCs in several cells in which ethanol inhibited NMDA EPSCs induced by $5 \mathrm{~Hz}$ stimulation.

\section{Conclusions}

The major findings of this study include the following: (1) $5 \mathrm{~Hz}$ stimulation of the inner molecular layer of the dentate gyrus induced hyperexcitability of synaptic responses that required the activation of $\mathrm{GABA}_{\mathrm{B}}$ receptors, and was expressed by NMDA receptor-mediated currents; (2) hyperexcitability due to paired stimulation was blocked by ethanol in a dose-dependent manner at pharmacologic concentrations; (3) repetitive $5 \mathrm{~Hz}$ stimulation for $2 \mathrm{sec}$ to the inner molecular layer induced nondecremental LTP of synaptic transmission; (4) synaptic plasticity due to 5 $\mathrm{Hz}$ trains was completely prevented by ethanol $(75 \mathrm{~mm})$ in a reversible manner; (5) $5 \mathrm{~Hz}$ stimulation caused fading of pharmacologically isolated GABAergic synaptic currents (mIPSCs); 

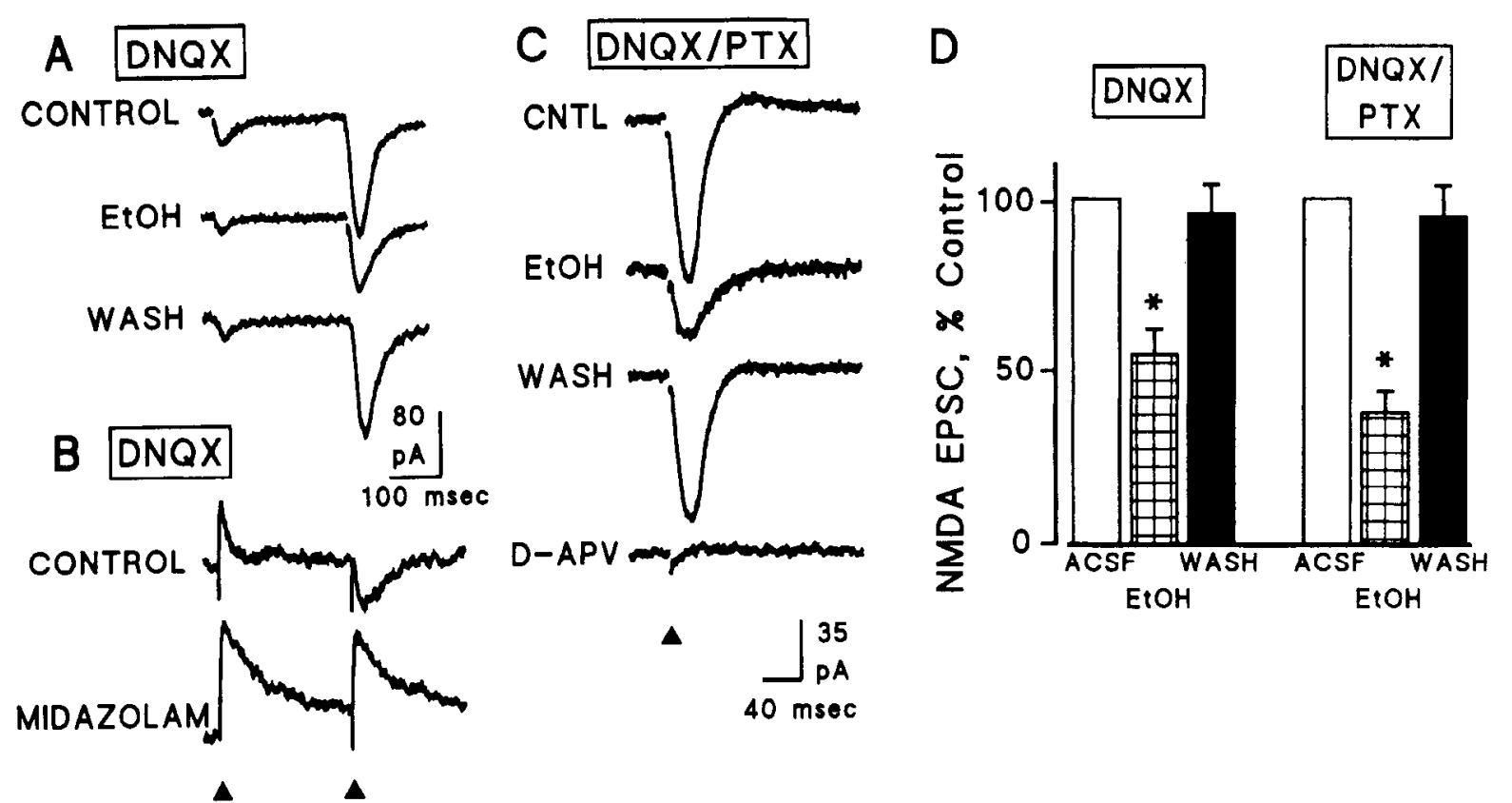

Figure 5. Ethanol blocks NMDA EPSCs in dentate gyrus. $A$, The effect of ethanol (75 mM) on NMDA EPSCs recorded in the presence of DNQX $(10 \mu \mathrm{M})$, induced by $5 \mathrm{~Hz}$ stimulation and recorded at $-75 \mathrm{mV}$. Stimulation in this manner elicited a large increase in the inward current due to the second stimulus. Ethanol strongly inhibited the NMDA EPSCs due to $5 \mathrm{~Hz}$ stimulation having little effect on the control response. Test and conditioned EPSCs recorded in DNQX $(10 \mu \mathrm{M})$ were inhibited $78 \pm 3 \%$ and $85 \pm 4 \%$, respectively, by D-APV (25 $\mu \mathrm{M}$, not shown). $B$, The benzodiazepine midazolam $(30 \mu \mathrm{M})$ potentiates the GABAergic currents (outward currents at first stimulus) and completely reverses the effect of $5 \mathrm{~Hz}$ stimulation abolishing the inward currents. Calibration bars apply to $A$ and $B$. $C$, NMDA EPSCs recorded in DNQX (10 $\mu \mathrm{M})$ and the GABA channel antagonist PTX $(25 \mu \mathrm{M})$ and elicited by single stimuli are blocked by ethanol in a reversible manner. D-APV (25 $\mu \mathrm{M})$ inhibited DNQX/ PTX NMDA EPSCs by $86 \pm 4 \%$. D, Cumulative data for ethanol inhibition of NMDA EPSCs elicited by $5 \mathrm{~Hz}$ stimulation (at left in DNQX) and by single stimuli (at right in DNQX/PTX). For both ethanol cases, NMDA EPSCs were significantly different ( ${ }^{*}, p<0.01$, Kruskal-Wallis, $n=9$, 6 cells in DNQX and DNQX/PTX, respectively).

(6) the mIPSCs and fading of the mIPSCs were insensitive to ethanol at concentrations that inhibited hyperexcitability and LTP; (7) pharmacologically isolated NMDA EPSCs were inhibited by ethanol at the same concentration that blocked hypcrexcitability and LTP.

Taken together, these data indicate that, in the perforant pathdentate gyrus synapse, the ability of ethanol to inhibit thetainduced hyperexcitability and LTP is via direct inhibition of an NMDA receptor-mediated ion current. The lack of an effect of ethanol on GABAergic responses (or their autoregulation) obtained in this study strongly suggests that the pharmacologic effects of ethanol on hippocampal excitability and plasticity are mediated through effects on the NMDA receptor-channel complex. Additionally, the lack of an effect of ethanol on the peak field EPSP amplitude suggests that non-NMDA receptor-mediated responses at the perforant path synapses are largely ethanol insensitive.

The induction of LTP is dependent upon increasing intracellular calcium concentrations (Malenka et al., 1988). This can bc accomplished through tetanic stimulation that releases the $\mathrm{Mg}^{2+}$ block of the NMDA channel (Herron et al., 1986), or by incubation in buffer having increased calcium concentrations (Turner et al., 1982). The previous reports of ethanol inhibition of LTP all utilized induction paradigms that promoted calcium influx under either of these circumstances (predominantly highfrequency trains). However, GABAergic inhibition plays a major role in regulating the induction of LTP as well (Wigstrom and Gustafsson, 1983). In this report, we utilized induction paradigms to model the physiologic activation of hippocampal NMDA receptor-mediated responses under conditions in which
GABAergic inhibition has been shown to play a crucial role (Davies et al., 1991; Mott et al., 1991). The present findings are in accord with the previous reports of ethanol inhibition of LTP. Howcver, the present study directly compares the effects of ethanol on GABAergic inhibition and NMDA receptor-mediated excitation on synaptic currents in the dentate gyrus. Using this methodology, the specificity of ethanol effects on these neurotransmitter systems has been dissected.

The present data support the conclusion that ethanol blocks LTP by virtue of blocking NMDA synaptic currents. Electrophysiologic and biochemical evidence that ethanol selectively inhibits NMDA receptor-mediated responses is now quite strong (Hoffmann et al., 1989; Lovinger et al., 1989; Woodward and Gonzales, 1990; Morrisett et al., 1991c). As a result, understanding the physiologic consequences of ethanol exposure on NMDA systems is of great interest. Chronic ethanol exposure is associated with an increase in ${ }^{3} \mathrm{H}-\mathrm{MK}-801$ binding site density, indicating that long-term ethanol exposure may upregulate NMDA channel number (Grant et al., 1990; Valverius et al., 1990; Gulya et al., 1991). Such alterations in NMDA receptor pharmacology strongly support the possibility that some of the behavioral effects of chronic ethanol exposure and withdrawal could be mediated through the NMDA receptor-channel complex.

Evidence of specificity of the actions of ethanol at ligandgated ion channels as demonstrated in this report is strong. Concerning NMDA receptors, several investigators have rcported some noncompetitive interactions of ethanol with glycine (Rabe and Tabakoff, 1990; Woodward and Gonzales, 1990) and $\mathrm{Mg}^{2+}$ binding sites (Martin et al., 1991; Morrisett et al., 1991c). 
Such findings appear to indicate that channel conformation or activation state may be critical for ethanol-induced inhibition of NMDA responses. Strong evidence supporting the specificity of action of depressant agents at ion channels includes the recent report of stereospecificity between isoflurane optical isomers at voltage-gated ion $\mathrm{K}^{+}$channels (Franks and Leib, 1991). This is further supported by the observation that ethanol has little effect on AMPA responses and intermediate effects on kainate responses (Lovinger et al., 1989). These results are supported by the present data demonstrating ethanol inhibition of NMDA receptor-mediated prolongation of population synaptic responses (Figs. 2, 3) while leaving the non-NMDA synaptic response unaltered.

Concerning the specificity of ethanol action at GABA channel complex, the present results indicate that ethanol does not potentiate GABAergic systems in dentate. These data are in good accord with the recent findings of Proctor et al. (1992), who demonstrated ethanol potentiation of $\mathrm{GABA}_{\mathrm{A}}$ synaptic responses in cerebral cortex and cerebellum but not in hippocampus. Howcver, scveral investigators have demonstrated that ethanol, at pharmacologic concentrations, potentiates the uptake of $\mathrm{Cl}^{-}$stimulated by GABA (Allan and Harris, 1986; Suzdak, 1986; Ticku, 1987). The literature regarding the effects of ethanol on electrophysiologic responses mediated by GABA receptors has been varied (compare Davidoff, 1973; Nestoros, 1980; Celentano et al., 1988; with Mancillas et al., 1986; Harrison et al., 1987). Nevertheless, Siggins et al. (1987) and Aguayo (1990) have reported electrophysiologic evidence that ethanol potentiates GABA effects in the hippocampal formation and cultured cells. However, Wafford et al. (1991) have demonstrated the dependence of ethanol effects on $\mathrm{GABA}_{\mathrm{A}}$ subunit structure, suggesting that $\gamma$-subunit variants are differentially affected by ethanol depending upon the presence of specific sequence inserts in the third intracellular loop (Wafford et al., 1991), possibly related to the presence of phosphorylation sites. Direct mRNA measurement has demonstrated the presence of ethanolsensitive and -insensitive $\gamma$-subunits in the hippocampal formation (Buck et al., 1991). It is likely that the expression of ethanol-sensitive GABA subunits in the hippocampal formation is insufficient to permit the recording of an ethanol-sensitive GABAergic response electrophysiologically.

On the other hand, intracellular dialysis due to whole-cell recording may remove intracellular constituents required for ethanol potentiation of $\mathrm{GABA}_{\mathrm{A}}$ currents. In the present experiments we observed no time dependence of ethanol effects on either NMDA or $\mathrm{GABA}_{\mathrm{A}}$ currents. We did not observe ethanol potentiation of $\mathrm{GABA}_{\mathrm{A}}$ currents in cells exposed to ethanol immediately following obtaining whole-cell configuration versus those cells exposed to ethanol following longer periods prior to ethanol exposure. In other words, we observed no "rundown" of ethanol effects on either NMDA or GABA ${ }_{A}$ currents. This should have been especially apparent for the DNQX experiments versus the DNQX/PTX experiments. If ethanol inhibited the expression of NMDA currents by potentiation of $\mathrm{GABA}_{\mathrm{A}}$ currents under conditions of current rundown, then we should have observed rundown of ethanol inhibition of NMDA currents only under the circumstances of recording in DNQX and not in DNQX/PTX. Such effects were never observed.

The hippocampal formation is known to be critical for memory formation (Mahut et al., 1982), rich in NMDA receptors (Monaghan et al., 1983), and highly susceptible to the effects of ethanol (Swartzwelder, 1985). As these lines of evidence have converged, the amnesic effects of ethanol have been increasingly ascribed to effects on hippocampal function (Lovinger et al., 1989, 1990). The NMDA receptor-channel complex is a critical site for the induction of LTP in most hippocampal circuits; therefore, this receptor system would seem to be a likely target for one of the primary cognitive effects of ethanol. In the present study, we have utilized techniques to elicit NMDA-mediated responses under conditions similar to those required for physiologic expression. The present findings indicate that NMDA responses under such conditions exhibit sensitivity to ethanol at pharmacologic concentrations. These findings are also unique in that they include direct demonstration of ethanol inhibition of synaptically activated NMDA receptor-mediated ion current. Taken together, these results provide evidence that the behavioral effects of intoxicating concentrations of ethanol may be elicited predominantly by an interaction at the NMDA channel complex.

\section{References}

Aguayo LG (1990) Ethanol potentiates the GABA $A_{A}$-activated Cl current in mouse hippocampal and cortical neurons. Eur J Pharmacol $187: 127-130$

Allan AM, Harris RA (1986) Gamma-aminobutyric acid and alcohol actions: neurochemical studies of long sleep and short sleep mice. Iife Sci 39:2005-2015

Barnes CA (1979) Memory deficits associated with senescence: a neurophysiological and behavioral study in the rat. J Comp Physiol Psychol 93:74-104.

Berger TW (1984) Long-term potentiation of hippocampal synaptic transmission affects rate of behavioral learning. Science 224:627-630.

Blanton MG, Lo Turco JJ, Kreigstein AR (1989) Whole cell recording in slices of reptilian and mammalian cerebral cortex. J Neurosci Methods 30:203-210.

Blitzer RD, Gil O, Landau EM (1990) Long-term potentiation in rat hippocampus is inhibited by low concentrations of ethanol. Brain Res 537:203-208.

Buck KJ, Sikela JM, Harris RA (1991) Expression of GABA $A_{A}$ receptor subunit mRNA's in long- (LS) and short-sleep (SS) mouse brain regions: analysis by the polymerase chain reaction (PCR). Alcohol Clin Exp Res 15:320.

Celentano JJ, Gibbs TT, Farb DH (1988) Ethanol potentiates GABAand glycine induced chloride currents in chick spinal cord neurons. Brain Res 455:377-380.

Cohen S, Martin D, Morrisett RA, Wilson WA, Swartzwelder HS (1991)In vitro effects of ethanol on hippocampal electrographic seizures. Soc Neurosci Abstr 17:1601.

Collingridge GL, Kehl SJ, McLennan H (1983) Excitatory amino acids in synaptic transmission in the Schaffer collateral-commissural pathway of the rat hippocampus. J Physiol (Lond) 334:33-46.

Davidoff RA (1973) Alcohol and presynaptic inhibition in an isolated spinal cord preparation. Arch Neurol 28:60-63.

Davies CE, Davies SN, Collingridge GL (1990) Paired-pulse depression on monosynaptic GARA-mediated inhibitory post-synaptic responses in rat hippocampus. J Physiol (Lond) 424:513-531.

Davies CE, Starkey SJ, Pozza MF, Collingridge GL (1991) GABA autoreceptors regulate the induction of LTP. Nature 349:609-611.

Diamond DM, Dunwiddie TV, Rose GM (1988) Characteristics of hippocampal primed burst potentiation in vitro and in the awake rat. J Neurosci 8:4079-4088.

Diesz RA, Prince DA (1989) Frequency-dependent depression of inhibition in guinea pig neocortex in vitro by $\mathrm{GABA}_{\mathrm{B}}$ receptor feedback on GABA release. J Physiol (Lond) 412:513-542.

Durand D, Carlen PL (1984) Impairment of long-term potentiation in rat hippocampus following chronic ethanol treatment. Brain Res 308:325-332.

Franks NP, Leib WR (1991) Stereospecific effects of inhalational general anesthetic optical isomers on nerve ion channels. Science 254: $427-430$.

Grant KA, Valverius P, Hudspith M, Tabakoff B (1990) Ethanol withdrawal seizures and the NMDA receptor complex. Eur J Pharmacol 176:289-296. 
Gulya K, Grant KA, Valverius P, Hoffman PL, Tabakoff B (1991) Brain regional specificity and time-course of changes in the NMDA receptor-ionophore complex during ethanol withdrawal. Brain Res 547:129-134.

Hamill OP, Marty A, Sakmann B, Sigworth F (1981) Improved patchclamp techniques for high resolution current recordings from cells and cell-free membrane patches. Pfluegers Arch 391:85-100.

Harrison NL, Majewska MD, Harrington JW, Barker JL (1987) Structure activity relationships for steroid interaction with gamma-aminobutyric acid-a receptor complex. J Pharmacol Exp Ther 241:346353.

Herron CE, Lester RAJ, Coan EJ, Collingridge GL (1986) Frequencydependent involvement of NMDA receptors in the hippocampus: a novel synaptic mechanism. Nature 322:265-268.

Hoffman PL, Rabe CS, Moses F, Tabakoff B (1989) NMDA receptors and ethanol: Inhibition of calcium flux and cyclic GMP production. J Neurochem 52:1937-1940.

Larson J, Lynch G (1986) Induction of synaptic potentiation in hippocampus by patterned stimulation involves two events. Science 232: 985-988.

Lima-Landman T, Albuquerque EX (1989) Ethanol potentiates and blocks NMDA-activated single-channel currents in rat hippocampal pyramidal cells. FEBS Lett 247:61-67.

Lovinger DM, White G, Weight FF (1989) Ethanol inhibits NMDAmediated ion current in hippocampal neurons. Science 243:17211724.

Lovinger DM, White G, Weight FF (1990) NMDA receptor-mediated synaptic excitation selectively inhibited by ethanol in hippocampal slice from adult rat. J Neurosci 10:1372-1379.

Mahut HS, Zola-Morgan S, Squire LS (1982) Hippocampal resections impair associative learning and recognition memory in the monkey. J Neurosci 2:1214-1229.

Malenka RC, Kauer JA, Zucker RS, Nicoll RA (1988) Postsynaptic calcium is sufficient for potentiation of hippocampal synaptic transmission. Science 242:81-84.

Mancillas J, Siggins GR, Bloom FE (1986) Systemic ethanol: selective enhancement of responses to acetylcholine and somatostatin in the rat hippocampus. Science 231:161-163

Martin D, Morrisett RA, Bian X-P, Wilson WA, Swartzwelder HS (1991) Ethanol inhibition of NMDA-mediated depolarizations is increased in the presence of $\mathrm{Mg}^{++}$. Brain Res 546:227-234.

Mello N (1972) Behavioral studies of alcoholism. In: The biology of alcoholism, Vol 2(Kissin B, Begleiter H, eds), pp 219-291. New York: Plenum.

Monaghan DT, Holets VR, Toy DW, Cotman CW (1983) Anatomic distributions of four pharmacologically distinct $\left[{ }^{3} \mathrm{H}\right]$-glutamate binding sites. Nature 306:176-179.

Morris RGM, Anderson E, Lynch GS, Baudry M (1986) Selective impairment of learning and blockade of long term potentiation by an NMDA receptor antagonist, AP5. Nature 319:774-776.

Morrisett RA, Rezvani AH, Overstreet D, Janowsky DS, Wilson WA, Swartzwelder HS (1990) MK-801 potently inhibits alcohol withdrawal seizures in rats. Eur J Pharmacol 176:103-105.

Morrisett RA, Wilson WA, Swartzwelder HS (1991a) Evidence that ethanol reduces $\mathrm{GABA}_{\mathrm{B}}$-mediated disinhibition and synaptic plasticity induced by a priming paradigm in rat dentate gyrus. Soc Neurosci Abstr 17:1169.

Morrisett RA, Mott DD, Lewis DV, Swartzwelder HS, Wilson WA (1991b) $\mathrm{GABA}_{\mathrm{B}}$-receptor mediated inhibition if the $N$-methyl-D-aspartate component of synaptic transmission in the rat hippocampus. J Neurosci 11:203-209.

Morrisett RA, Martin D, Oetting TA, Lewis DV, Wilson WA, Swartzwelder HS (1991c) Ethanol and $\mathrm{Mg}^{++}$inhibit NMDA mediated synaptic potentials in an interactive manner. Neuropharmacology 30 : 1173-1178.

Mott DD, Lewis DV (1991) Facilitation of the induction of LTP by $\mathrm{GABA}_{\mathrm{B}}$ receptors. Science 252:1718-1720.

Mulkeen D, Anwyl R, Rowan MJ (1987) Enhancement of long-term potentiation by the calcium channcl agonist BAY K8644 in CAl of the rat hippocampus in vitro. Neurosci Lett 80:351-355.

Nathan T, Lambert JDC (1991) Depression of the fast IPSP underlies paired-pulse facilitation in area CAl of the rat hippocampus. J Neurophysiol 66:1704-1715.

Nathan T, Jensen MS, Lambert JDC (1990) GABA $_{\mathrm{B}}$ receptors play a major role in pair-pulse facilitation in area $\mathrm{CAl}$ of the rat hippocampus. Brain Res 531:55-65.

Nestoros JN (1980) Ethanol specifically potentiates GABA-mediated neurotransmission in the feline cerebral cortex. Science 209:708-710.

Nowak L, Bregestovski P, Ascher P, Herbert A, Prochiantz A (1984) Magnesium gates glutamate-activated channels in mouse central neurones. Nature 307:462-465.

Pacelli GJ, Su W, Kelso SR (1989) Activity-induced depression of synaptic inhibition during LTP-inducing patterned stimulation. Brain Res 486:26-32.

Pavlides C, Greenstein YJ, Grudman M, Winsom J (1988) Long-term potentiation in the dentate gyrus is produced preferentially on the positive phase of $\theta$ rhythm. Brain Res 439:383-387.

Proctor WR, Allan AM, Dunwiddie TV (1992) Brain regional-dependent sensitivity of $\mathrm{GABA}_{\mathrm{A}}$ receptor-mediated responses to modulation by ethanol. Alcohol Clin Exp Res 16:480-489.

Rabe C, Tabakoff B (1990) Glycine site-directed agonists reverse the actions of ethanol the NMDA receptor. Mol Pharmacol 38:753-757.

Siggins GR, Pittmann QJ, French ED (1987) Effects of ethanol on CA 1 and CA3 pyramidal cells in the hippocampal slice preparation: an intracellular study. Brain Res 414:22-34.

Sinclair JG, Lo GF (1986) Ethanol blocks tetanic and calcium-induced long term potentiation in the hippocampal slice. Gen Pharmacol 17: 231-233.

Streissguth AP, Herman CS, Smith DW (1978) Intelligence, behavior and dysmorphogenesis in the fetal alcohol syndrome: a report in 20 patients. J Pediatr 92:363-367.

Streissguth A, Barr H, Sampson P (1990) Moderate prenatal alcohol exposure: effects on child I.Q. and learning problems at age $71 / 2$ years. Alcohol Clin Exp Res 14:662.

Suzdak PD, Schwartz RD, Skolnick P, Paul SM (1986) Ethanol stimulates gamma-aminobutyric acid receptor mediated chloride transport in rat brain synaptneurosomes. Proc Natl Acad Sci USA 83: $4071-4075$.

Swartzwelder HS (1985) Hippocampal involvement in the effects of ethyl alcohol: in-vivo and in-vitro levels of analysis. In: In-vivo perfusion and release of neuroactive substances (Bayon A, Drucker-Colin R, eds), pp 201-220. Orlando, FL: Academic.

Swartzwelder HS, Farr KL, Wilson WA, Savage DD (1988) Prenatal ethanol exposure decreases physiological plasticity in the rat hippocampal slice. Alcohol 5:121-124.

Teyler T, DiScenna P (1984) Long-term potentiation as a candidate mnemonic device. Brain Res Rev 7:15-28.

Teyler T, DiScenna P (1985) The role of hippocampus in memory; a hypothesis. Neurosci Biobehav Rev 9:377-389.

Ticku MK (1987) Behavioral and functional studies indicate a role of GABAergic transmission in the actions of ethanol. Alcohol Alcohol [Suppl] 1:657-662.

Turner RW, Bainbridge KG, Miller JJ (1982) Calcium-induced longterm potentiation in the hippocampus. Neuroscience 7:1411-1416.

Valverius P, Crabbe JC, Hoffman PL, Tabakoff B (1990) NMDA receptors in mice breed to be prone or resistant to alcohol withdrawal seizures. Eur J Pharmacol 184:185-189.

Vanderwolf $\mathrm{CH}$ (1969) Hippocampal electrical activity and voluntary movement in the rat. Electroencephalogr Clin Neurophysiol 26:407418.

Wafford KA, Burnett DM, Leidenheimer NJ, Burt DR, Wang JB, Kofuji P, Dunwiddie TV, Harris RA, Sikela JM (1991) Ethanol sensitivity of the GABA receptor expressed in Xenopus oocytes requires 8 amino acids contained in the gamma-2L subunit. Neuron 7:27-33.

Walker DW, Hunter BE (1978) Short-term memory impairment following chronic alcohol consumption in rats. Neuropsychologia 16 : 545-553.

West JR, Hodges CC, Black AC (1981) Prenatal exposure to ethanol alters the organization of hippocampal fibers in rats. Science 211 : 957-959

Wigstrom H, Gustafsson B (1983) Facilitated induction of hippocampal long-lasting potentiation during blockade of inhibition. Nature 301:603-604.

Winson J (1974) Patterns of hippocampal theta rhythm in the freely moving rat. Electroencephalogr Clin Neurophysiol 36:291-301.

Woodward JJ, Gonzales RA (1990) Ethanol inhibition of NMDAstimulated endogenous dopamine release from rat striatal slices: reversal by glycine. J Neurochem 54:712-715. 